\title{
Inferior Vena Cava Filters-Current Role and Controversies
}

\author{
Harit Kapoor ${ }^{1}$ Driss Raissi² \\ ${ }^{1}$ Department of Radiology, University of Kentucky College of \\ Medicine, Lexington, Kentucky, United States \\ 2Department of Interventional Radiology, University of Kentucky \\ College of Medicine, Lexington, Kentucky, United States
}

\author{
Address for correspondence Harit Kapoor, MD, Department of \\ Radiology, University of Kentucky Medical Center, 800 Rose Street, HX \\ 315, Lexington, KY 40536, United States \\ (e-mail: haritkapoor@uky.edu).
}
Abstract
Keywords
- inferior vena cava filter
- venous thromboembolism
- retrievable filter
- anticoagulation
- temporary filter
- optional filter
- superior vena cava
filter

Inferior vena cava filters (IVCFs) remain an indispensable part of an interventionalist's toolbox. Increased recognition of filter-related complications, largely from off-label use and casual approach to filter retrieval, has led to tremendous uncertainty surrounding their use. More stringent regulations on their use and development of newer and safer anticoagulants are gradually changing their role in the management of venous thromboembolism. Herein, the authors review the current role of IVCFs, indications for their use and retrieval, as well as filter-related complications.

\section{Introduction}

Patients with concurrent risk for venous thromboembolism (VTE) and hemorrhage pose a daily medical dilemma, as anticoagulation may be contraindicated. Anticoagulation is the mainstay for VTE prophylaxis and treatment. Those with absolute contraindications to anticoagulation may benefit from inferior vena cava filter (IVCF) placement to prevent an impending or recurring embolism. However, quantification of risk for either VTE or hemorrhage is quite subjective, both in terms of the intensity and duration of elevated risk. This subjectivity is well reflected within the heterogeneity of the multiple societal guidelines on IVCF placement. ${ }^{1}$

Currently, approximately $15 \%$ of patients admitted with acute VTE will receive an IVCF. ${ }^{2}$ Since the development of retrievable IVCFs (rIVCF), a sharp sinusoidal trend in use has been seen. A steep rise in IVCF use was noted in the early 2000s, which declined precipitously after increased recognition of their long-term risks, specifically after warnings by the Food and Drug Administration (FDA). Additionally, lowering of Medicare reimbursements in $2012^{3}$ and multiple medicolegal lawsuits ${ }^{4}$ that gained widespread media attention also contributed to this decline. However, a correctional trend is seen in the more recent literature. ${ }^{5}$ Interventional radiology consultation approach to IVCF

received

October 27, 2018

accepted after revision

January 7, 2019

published online

April 24, 2019 placement with planned follow-up has been shown to improve filter-related outcomes. ${ }^{6}$

In-depth knowledge of the underlying disease pathophysiology and tailoring the available body of evidence to the individual patient scenario are of paramount importance in making a judgment on the choice and technical feasibility of filter placement and/or retrieval. This review presents an update on the current role of IVCF that is supported by best available evidence to facilitate judicious clinical use of rIVCF and provide a glimpse of recent developments that would affect their use in the future.

\section{Dynamic Risk Assessment in a Patient Referred for Inferior Vena Cava Filter}

A multitude of prothrombotic and hemorrhagic factors are usually at play in a hospitalized patient. Establishing the baseline risk status in this dynamic spectrum is essential in decision making regarding further therapy (anticoagulation, its duration, and the need for IVCF). Two factors need to be assessed:

1. Assessment of risk of hemorrhage: Hemorrhagic risk (generalized or organ specific), especially when high, is given the upper hand in deciding whether the patient can receive therapeutic anticoagulation. ${ }^{7}$
License terms

()(1) $\Theta \circledast$
$10.1055 / \mathrm{s}-0039-1685236$ ISSN 2457-0214. 
2. Assessment of risk of deep vein thrombosis (DVT)VTE recurrence: When plausible risk factors for DVT are identifiable, it is said to be "provoked." Instead, when no identifiable factors are present, a DVT is referred to as "unprovoked." ${ }^{\mathrm{A}}$ provoked DVT-VTE implies a more temporary risk and is considered to be less likely to recur, whereas the unprovoked DVT is often associated with a permanent risk factor and, as such, is considered more likely to recur. ${ }^{9}$ The duration of anticoagulation, or alternatively the choice of retrievable versus permanent filter, depends on the estimated period of elevated prothrombotic risk.

\section{Rationale for Inferior Vena Cava Filter Use}

Inferior vena cava filters are mechanical devices placed typically in the infrarenal IVC to prevent migration of large thrombi up into the cardiopulmonary system, while maintaining relatively unimpeded venous outflow from the lower extremities. They neither treat the existing venous thrombosis nor prevent local thrombus progression. Ironically, with prolonged dwell time, IVCFs themselves, being an intravascular foreign body, can incite thrombosis and become occluded. All considered, the modern-day rIVCFs with their ease of placement and retrievability, are still a significant medical advancement as they allow for prevention of fatal VTE in the acute high-risk period while avoiding potential long-term IVCF-related complications. It is vital that rIVCF use be perceived as a temporizing measure, essentially allowing for postponement of final decision making on appropriateness of anticoagulation. This final decision should be based on periodic follow-ups with longitudinal assessment of the continual presence or lack of IVCF indications.

\section{Inferior Vena Cava Filter Indications}

Many professional groups have guidelines regarding filter insertion; these guidelines vary widely and often conflict. On the one hand, the American College of Chest Physicians (ACCP) guidelines recommend restricting their use to the so-called classic indications where their use is clearly the only available option..$^{10}$ On the other hand, the American College of Radiology and Society of Interventional Radiology guidelines allow for much more liberal use of rIVCFs in prophylactic situations for patients at high risk of developing VTE, divided into "expanded" and "prophylactic" subset of indications. ${ }^{11}$ This has led to a large variation in IVCF utilization in the past two decades, both internationally and even between different types of practices within the United States. ${ }^{12}$ An international effort at web-based rIVCF registry in the post-FDA-warning period shows a decreased proportion of prophylactic insertions compared with those for classic indications, 24 and $40 \%$, respectively. ${ }^{13}$

\section{Modern Inferior Vena Cava Filter Design and Functionality}

Ideal IVCF should be safe and easy to deploy, be least thrombogenic, be able to securely attach to the IVC wall, and function with high efficiency. Based on intended

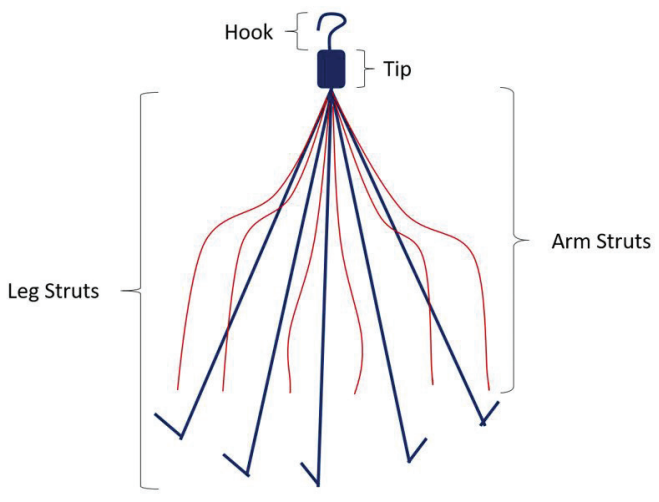

Fig. 1 Prototypical conical retrievable IVCF and its component parts-tip with hook, arm struts, and leg struts.

purpose and duration of use, IVCFs can be divided into five types: permanent, retrievable, temporary, convertible, and biodegradable. The permanent filters are designed to remain and get incorporated into IVC wall whereas retrievable filters are recommended for temporary use and should be ideally retrieved within 30 to 59 days. - Fig. 1 demonstrates the design of a prototypical retrievable filter. The latter three categories are newer subtypes with limited data so far to support their clinical use. Largely, these categories are strictly for use where the VTE risk is definitively temporary like in a perioperative setting. A temporary filter is tethered to an external catheter or wire for removal within 30 days. Convertible filters are permanent implants that get converted into a stent through a subsequent conversion procedure or spontaneously after a certain period of time. Recently, 1-year follow-up data from the first 100 patients were published for the autoconvertible Sentry filter (Novate Medical) with encouraging results. ${ }^{14}$ Biodegradable filters are filters made completely with special biodegradable materials that allow for delayed disintegration of the filter at approximately 10 weeks post-insertion. ${ }^{15}$

\section{Current Evidence on Filter Efficacy}

No randomized controlled trials (RCTs) exist that directly compare the use of IVCF alone versus anticoagulation alone because ethical approval for filter use in patients who are not anticoagulated is impracticable. All current data pertain to the comparison between IVCF with and without anticoagulation.

\section{Prospective Studies}

Only two relatively small prospective randomized studies have been carries out by the same group. The landmark PREPIC (Prevention du Risque d'Embolie Pulmonaire par Interruption Cave) trial in 1998 randomized 400 patients with proximal DVT to receive adjunctive filter versus only anticoagulation. Permanent filters and conventional anticoagulants were used. At 2 years, while symptomatic VTE occurred with increased frequency in the nonfilter group, it remained short of statistical significance. On follow-up at 8 years in 2005, difference in VTE rate achieved statistical 
significance; interestingly, however, one-half of the patients discontinued anticoagulation after 6 months of treatment, and most of the recurrences occurred after anticoagulation was stopped. Also, of note, there were significantly more symptomatic DVTs in the filter group with no difference in overall mortality. ${ }^{16}$

The PREPIC group published results from another RCT in 2015-PREPIC II with similar study parameters (400 patients with documented VTE randomized to adjunctive filter versus only anticoagulation) but with the use of rIVCFs. This study had unexpectedly low and comparable rates of VTE in the control group, thus implying futility of IVCF placements and removals in the test arm. Also, of note, an increase in DVT with IVCF use was not seen this time around, reinforcing the benefits of filter removal within 3 months, which was part of the study protocol. ${ }^{17}$

However, the results of both these trials are inapplicable to patients with classic indications who are most in need for IVCFs and cannot receive anticoagulation.

\section{Retrospective Studies}

Three large population-based studies have had major impact on IVCF literature:

1. Stein and Matta in 2014 evaluated outcomes of 19,480 IVCF placements in unstable patients with shock or ventilator dependence from a total of $>2$ million unstable patients in the U.S. Nationwide Inpatient Sample (NIS) database (1999-2008). They showed that IVCF use, both standalone and adjunctive, reduced the in-hospital allcause mortality in these unstable patients with VTE, with the greatest benefit achieved in patients aged $>81$ years. ${ }^{18}$

2. White et al in 2016 compared outcomes of adjunctive versus standalone IVCF use in 80,697 and 3,017 patients, respectively, by using the California statewide patient discharge database. They showed significant reduction in short-term risk of death only with standalone IVCF use for classic indications. ${ }^{19}$

3. Wadhwa et al in 2018 evaluated 67,237 prophylactic IVCF placements in patients with congestive heart failure (CHF) from a total of $>400,000$ CHF patients using the U.S. NIS database (2005-2014). They found significant all-cause mortality benefit in these VTE patients with CHF who received a IVCF while hospitalized. ${ }^{20}$

\section{Inferior Vena Cava Filter-Related Complications}

\section{Definitions and Consensus on Safe IVCF Placement}

In 2011, SIR established a long-due consensus document to guide standards of practice. They precisely defined the complications and set up acceptability thresholds for technical success. An overall technical complication rate of $<3 \%$ was considered acceptable. Specifically, $\leq 1 \%$ for rate of filter embolization or death and $a \leq 3 \%$ for rate of accesssite thrombosis. ${ }^{21}$ In a recent study by Oh and Hingorani, in which they looked at $>300$ lawsuits related to IVCFs, the most common complication reported was a primary failure to prevent pulmonary embolism (PE). ${ }^{14}$ Clinically significant VTE can occur even in the presence of an IVCF, either secondary to ineffective IVC filtration by migrated or maloriented filter or due to embolic thrombus propagation via a parallel collateral channel.

\section{Understanding Popular Data on Filter-Related Complications}

It is important to make the patients and referring physicians understand that the data from the much popularized FDA MAUDE database is not an accurate estimate of true prevalence of complications, given that it only includes voluntary patient-reported events and does not take into account the denominator of total filter placements. ${ }^{11-17}$ On the other hand, the overall body of data looking specifically at IVCF-related complications may be underestimating the true incidence, given the fact that most filter-related complications are asymptomatic ${ }^{22}$ and routine imaging follow-up post-placement is not done is most practices.

\section{Core Facts on Filter-Related Complications}

Even though we do not have a true estimate of IVCF-related complications, we do know two core facts about them.

1. Although complications may occur at any point post-implantation, the majority occur following a prolonged dwell time. There is no absolute consensus on the length of time a filter can be left in place before removal can be safely attempted. Most manufacturers do not mention a recommended retrieval period that understandably corresponds to the fact that FDA approves only devices that can be left in place safely permanently. Various major studies and meta-analyses show a trend of increasing complications when the filters are left in place for longer periods. ${ }^{23}$ Morales et al using a decision analysis model inferred that retrieval between 29 and 54 days after placement balances the risk of VTE versus the filter-related complications, which has been incorporated by the most recent FDA update. ${ }^{24}$

2. Retrievable IVCF have consistently shown much higher complication rates in multiple studies, even though not proven by any RCT. ${ }^{23,25}$ Among rIVCFs, newer filter designs have been shown to perform better with lower complication rates than older devices. Recently, Deso et al from Stanford University compared the maximum reported filter-related complications between different filter geometries. They noted a generalized trend of higher perforation and fracture among conical filters and higher rates of IVC occlusion with those having a cylindrical or umbrella element. ${ }^{26}$

\section{Retrieval of Inferior Vena Cava Filter}

Concept of retrievability: Although retrieval is highly recommended when using rIVCFs, they are made such that they are FDA approved as permanent devices keeping in consideration that patient's prothrombotic risk and risk factors against anticoagulation are dynamic. In 2013, Eifler et al showed that four clinical parameters were positively correlated with rIVCFs being declared permanent: advanced age, male sex, history of underlying malignancy, and history 
of anticoagulation failure. ${ }^{27}$ The primary actionable reasons underlying lower retrieval rates include poor clinical follow-up and inadequate explanation of long-term risks to the patients, besides the many other extrinsic social and practical factors. ${ }^{28,29}$

\section{Guidelines for Retrieval}

1. SIR guidelines propose the following criteria for appropriate discontinuation of IVCF $^{21}$ :

1. An indication for a permanent filter is not currently present.

2. The risk of clinically significant PE is estimated to be acceptably low due to sustained primary treatment (therapy or prophylaxis), or change has occurred in clinical status.

3. The patient is not anticipated to return to a highrisk state for PE because of interruption of primary treatment, change in clinical management, or change in clinical condition.

4. The life expectancy of the patient is long enough that the presumed benefits of discontinuation of filtration can be realized.

Recently in 2017, ACR-SIR jointly included a 3 month post-procedural assessment for retrieval as a quality metric as part of their national quality strategy for effective clinical care. ${ }^{23}$

2. The ACCP guidelines recommend initiation of anticoagulant therapy in all patients with an indwelling IVCF once their risk of bleeding resolves, with the intent of early filter retrieval. It is however, a grade $2 \mathrm{~B}$ recommendation secondary to conflicting data from studies comparing morbidity and mortality among all those with an IVCF who receive anticoagulation while still having an indwelling filter compared with those who do not. ${ }^{30}$

Newer techniques and better outcomes: With increasing concerns related to retained filters, progressively more retrievals are being done today. This has led to newer techniques being developed and improvement in retrieval outcomes even with longer dwell time as interventional radiologists and vascular surgeons get experienced and comfortable with these procedures. ${ }^{31}$ Even true permanent filters have been successfully retrieved. ${ }^{32}$

\section{Special Clinical Scenarios}

Special clinical scenarios are as follows (-Table 1):

1. IVCF use for isolated distal (infrapopliteal) DVT: Recent ACCP guidelines recommend expert judgment on risk factors for thrombus extension in this situation and managing either with serial ultrasound to image progression or prophylactic anticoagulation. IVCFs are not recommended for distal DVT. ${ }^{33}$

2. IVCF use for recurrence risk associated with isolated subsegmental emboli: ACCP guidelines recommend clinical surveillance over anticoagulation as the thromboembolic risk falls much short of the opposing risk of either prophylactic anticoagulation or temporary filter placement. In fact, subsegmental PE can be seen in up to $5 \%$ of thoracic CT scans performed for non-PE indications, especially in the subgroup of oncology patients. ${ }^{33}$

3. IVCF for expected prolonged interruption in anticoagulation: In select patients who require interruption of therapeutic anticoagulation for more than a brief period (48-72 hours), a prophylactic rIVCF may be considered after appropriate consultation and with the goal of IVCF retrieval once therapeutic anticoagulation can be resumed. rIVCF should not be used for a brief interruption and for patients on prophylactic anticoagulation.

4. IVCF for anticoagulation refractory or breakthrough VTE: Recurrent VTE despite anticoagulation is rare, and data on this topic are limited. It can be due to either a recalcitrant prothrombotic state like cancer or patient noncompliance, the latter being partly amenable to modification. Two approaches can be considered in such a scenario: change or escalation in the anticoagulation regimen to full therapeutic doses versus IVCF placement. The ACCP 2016 guidelines recommend the former approach with mention of IVCF placement as a last resort in these patients. This also applies to recurrence with newer agents..$^{10}$ There is, however, wide international variation in management of these patients. ${ }^{34}$

A large international registry by Shulman et al in 2015 showed less VTE recurrence with low-molecular-weight heparin (LMWH) compared with vitamin $\mathrm{K}$ analogues (VKAs). They also demonstrated acceptable safety of dose escalation, with an $8 \%$ major bleeding complication rate. ${ }^{34}$ Another retrospective study also showed similar success with escalated or modified anticoagulation regimens. ${ }^{35}$

5. IVC filter occlusion/thrombosis and its management: A true thrombosis (native formation of thrombus) within an IVCF cannot be differentiated from captured emboli from the lower extremities. A large retrospective review by Ahmed et al in 2010 found IVCF thrombosis in up to 19\% of patients with a denominator of 598 filter placements. Up to $84 \%$ of thrombosis occurred within the first 6 months after IVCF placement with a median of 35 days. ${ }^{36}$ Understandably, lack of routine post-procedural follow-up explains the lack reliability for data on late (> 6 months) filter-related thrombosis.

Asymptomatic thrombosis: In general, for asymptomatic thrombosis, manufacturer guidelines for conical filters recommend retrieval despite the presence of thrombus that occupies up to $25 \%$ of the filter cone, whereas those for nonconical designs discourage filter retrieval in the presence of any thrombus.

A widely followed management algorithm for the most commonly used conical filters was laid out by Habito and Kalva in 2011. ${ }^{37}$ They suggested that cases with $>25 \%$ thrombosis but otherwise none to minimal symptoms and acceptable IVCF orientation-anticoagulants for a minimum of 2 to 3 weeks can be tried before reassessment. However, available data on treatment success with this strategy are poor. In the aforementioned study by Ahmad et al, no significant difference in thrombus regression rates was seen on comparison on groups who did and did not receive short-term anticoagulation. ${ }^{36}$ 
Table 1 Evidence for IVCF use in special high-risk subgroups

\begin{tabular}{|c|c|c|c|c|}
\hline $\begin{array}{l}\text { High-risk } \\
\text { subgroups }\end{array}$ & Reasoning & Benefit & No benefit & Overall \\
\hline $\begin{array}{l}\text { Polytrauma } \\
\text { patients }\end{array}$ & $\begin{array}{l}\text { Prothrombotic risk with prolonged } \\
\text { immobilization and trauma-related } \\
\text { endothelial injury. Severe } \\
\text { hemorrhagic risk in head trauma } \\
\text { and significant solid organ trauma. } \\
\text { In mild-moderate hemorrhagic risk, } \\
\text { ACCP endorses the use of early anti- } \\
\text { coagulation since } 2008 \text { guidelines. }{ }^{10}\end{array}$ & $\begin{array}{l}\text { Rogers et al in } 1998^{49} \\
\text { Meta-analysis by Haut et al } \\
\text { in } 2014 .^{50}\end{array}$ & $\begin{array}{l}\text { Large systematic } \\
\text { reviews by Kidane } \\
\text { et al in } 2012 .^{51} \\
\text { Hemmila et al in } \\
2015^{51} \text { and Cook } \\
\text { et al in } 2017 . .^{53}\end{array}$ & $\begin{array}{l}\text { Conflicting evi- } \\
\text { dence/insufficient } \\
\text { to support use. } \\
\text { Overall decrease in } \\
\text { prophylactic use in } \\
\text { this population. }\end{array}$ \\
\hline $\begin{array}{l}\text { Bariatric } \\
\text { surgery } \\
\text { patients }\end{array}$ & $\begin{array}{l}\text { Morbid obesity is an independent } \\
\text { risk factor for VTE and weight- } \\
\text { based VTE prophylaxis using } \\
\text { anticoagulants alone is very } \\
\text { challenging in these patients. }\end{array}$ & $\begin{array}{l}\text { Gargiulo et al in } 2006 \text { for } \\
\text { open bariatric surgeries } \\
\text { and Vaziri et al in } 2009 \text { for } \\
\text { laparoscopic procedures. }\end{array}$ & $\begin{array}{l}\text { Systemic review } \\
\text { by Rowland et al in } \\
2015 . .^{56}\end{array}$ & $\begin{array}{l}\text { Conflicting evidence/ } \\
\text { insufficient to sup- } \\
\text { port use. Large vari- } \\
\text { ation in use among } \\
\text { North American } \\
\text { bariatric surgeons } \\
\text { with only } 28 \% \text { using } \\
\text { them routinely. }\end{array}$ \\
\hline $\begin{array}{l}\text { Pregnant } \\
\text { patients } \\
\text { (peripartum } \\
\text { period) }\end{array}$ & $\begin{array}{l}\text { Hypercoagulable state associated } \\
\text { with pregnancy takes effect, } \\
\text { beginning in the first trimester } \\
\text { and persists for up to } 2 \text { months } \\
\text { postpartum with compression of } \\
\text { IVC by gravid uterus in the last } \\
\text { trimester further increasing risk. } \\
\text { Anticoagulation in peripartum } \\
\text { period carries risk of severe } \\
\text { peripartum hemorrhage. }\end{array}$ & $\begin{array}{l}\text { A rIVCF can be used if } \\
\text { patient has a PE and/ } \\
\text { or DVT diagnosed in the } \\
\text { peripartum period, up to } \\
1 \text { month prior to expected } \\
\text { date of delivery. Systemic } \\
\text { review by Harris et al in } \\
2016^{57} \text { found total } 124 \\
\text { high-risk pregnancies } \\
\text { with IVCF placements and } \\
\text { showed safety and efficacy } \\
\text { data to be comparable to } \\
\text { general population. }\end{array}$ & $\begin{array}{l}\text { IVCF is not required } \\
\text { in the early } \\
\text { trimesters as pro- } \\
\text { phylactic low-mo- } \\
\text { lecular-weight } \\
\text { heparin can be } \\
\text { used (does not } \\
\text { cross the placenta). } \\
\text { Oral warfarin is con- } \\
\text { traindicated, and } \\
\text { none of the newer } \\
\text { anticoagulants are } \\
\text { approved. }\end{array}$ & $\begin{array}{l}\text { Insufficient evidence } \\
\text { to support prophy- } \\
\text { lactic use, however, } \\
\text { benefit in high-risk } \\
\text { pregnancies. }\end{array}$ \\
\hline $\begin{array}{l}\text { Cancer } \\
\text { patients }\end{array}$ & $\begin{array}{l}\text { Cancer is a prothrombotic state and } \\
\text { cancer-associated VTE is the second } \\
\text { leading cause of death in these } \\
\text { patients. Many of these patients have } \\
\text { high risk of refractory VTE despite } \\
\text { anticoagulation and on the other } \\
\text { hand and increased risk of bleeding } \\
\text { due to tumor and metastasis } \\
\text { hypervascularity. }\end{array}$ & $\begin{array}{l}\text { Meta-analysis by Noble } \\
\text { et al. in } 2008 .^{58}\end{array}$ & $\begin{array}{l}\text { Small RCT by } \\
\text { Barginear et al. in } \\
2012 . .^{59}\end{array}$ & $\begin{array}{l}\text { Insufficient data to } \\
\text { support prophylactic } \\
\text { use, however, as } \\
\text { many as } 19 \% \text { of } \\
\text { cancer patients } \\
\text { receive of IVCFs for } \\
\text { either on-label or } \\
\text { off-label use. }\end{array}$ \\
\hline
\end{tabular}

Abbreviations: ACCP, American College of Chest Physicians; DVT, deep vein thrombosis; IVCF, inferior vena cava filter; rIVCF, retrievable IVCF; PE, pulmonary embolism; RCT, randomized controlled trial; VTE, venous thromboembolism.

Symptomatic thrombosis: In cases of symptomatic acute to subacute thrombosis, usually due to a large clot burden, the patient may benefit from catheter-directed thrombolysis. ${ }^{38,39}$ Chronically thrombosed and difficult to retrieve filters are increasingly being managed with advanced techniques such as intravascular laser-assisted removal and stenting to lay open the IVC and permanently collapse the filter against the vena cava wall. These techniques have shown encouraging reported outcomes, but only from highly specialized IVCF removal centers. ${ }^{40}$

6. SVC filters: Upper-extremity DVT accounts for 5 to $10 \%$ of DVT. $^{41,42}$ The two greatest risk factors for upper-extremity DVT are central venous catheters and malignancy, and often these factors co-occur leading to a significantly high risk. ${ }^{43}$ VTE rate has been reported to be approximately $12 \%$ in patients with upper-extremity DVT.44 Placement of a superior vena cava (SVC) filter requires use of a modified technique and falls under the umbrella of off-label use. To maintain the correct orientation of the filter, a filter designed for jugular access is placed via a femoral approach, whereas the filter designed for femoral access is placed via a jugular approach. It is technically more demanding compared with an IVC filter placement, as the SVC has a shorter landing zone and is in close proximity to the brachiocephalic veins and right atrium. However, current data from experienced centers are promising, with good technical and clinical success even in high-risk patients. ${ }^{45-47}$ In a systematic review on 21 publications and 209 SVC filter placements by Owens et al, the overall complication rate was only $3.8 \%$ with major complications that included cardiac tamponade, aortic perforation, and recurrent pneumothorax. ${ }^{46}$

\section{IVCFs and newer direct oral anticoagulants (DOACs):} Newer direct oral anticoagulants (e.g., dabigatran, rivaroxaban, apixaban, and edoxaban) have been shown to be noninferior to VKA for long-term risk reduction in recurrent VTE while being superior to VKAs in terms of risk profile for bleeding and convenience of use both 
by the patient (orally administered as opposed to injectable) and physicians (wide therapeutic range allows for less patient oversight in a compliant patient). With FDA approval of direct anticoagulants since 2010 and interval generation of sufficient body of evidence, the recent ACCP 2016 guidelines favor longterm prophylaxis with DOACs over LMWH or VKAs in noncancer patients. ${ }^{7-10}$ Currently, targeted reversal agents are being pursued and being fast-tracked and granted breakthrough therapy designation by the FDA to encourage use and allay reservations in the emergent setting. ${ }^{48}$ Although still in their early implementation phase, these advantages of DOACs could potentially end up tipping the balance more in favor of pharmacologic anticoagulation and decrease the overall need for IVC filtration.

\section{Conclusion}

Inferior vena cava filter placement is not devoid of risk and should be considered on an individual patient basis in consultation with institution-specific experts. Prospective patient selection and responsible follow-up of nonpermanent filter placements with the goal of prompt retrieval when the patient has recovered becomes ambulatory and has reinitiated that anticoagulation should be emphasized. Prospective data from efforts at registry generation by the FDA, individual institutional endeavors at prudent use and newer advances in filter design, and use of newer anticoagulation agents hold significant promise for a more evidence-based approach to IVC filtration in the future.

\section{Conflict of Interest}

None.

\section{References}

1 Duffett L, Carrier M. Inferior vena cava filters. J Thromb Haemost 2017;15(1):3-12

2 White RH, Geraghty EM, Brunson A, et al. High variation between hospitals in vena cava filter use for venous thromboembolism. JAMA Intern Med 2013;173(7):506-512

3 Glocker RJ, TerBush MJ, Hill EL, et al. Bundling of reimbursement for inferior vena cava filter placement resulted in significantly decreased utilization between 2012 and 2014. Ann Vasc Surg 2017;38:172-176

4 Ahmed O, Jilani S, Heussner D, Khan M. Trapped by controversy: inferior vena cava filters and the law. J Vasc Interv Radiol 2017;28(6):886-888

5 Wadhwa V, Trivedi PS, Chatterjee K, et al. Decreasing utilization of inferior vena cava filters in post-FDA warning era: insights from 2005 to 2014 Nationwide Inpatient Sample. J Am Coll Radiol 2017;14(9):1144-1150

6 Ryu RK, Parikh P, Gupta R, et al. Optimizing IVC filter utilization: a prospective study of the impact of interventional radiologist consultation. J Am Coll Radiol 2012;9(9):657-660

7 Bartholomew JR. Update on the management of venous thromboembolism. Cleve Clin J Med 2017;84(12 (Suppl 3):39-46

8 Goldhaber SZ, Bounameaux H. Pulmonary embolism and deep vein thrombosis. Lancet 2012;379(9828):1835-1846
9 Rodger M, Carrier M, Gandara E, Le Gal G. Unprovoked venous thromboembolis: short term or indefinite anticoagulation? Balancing long-term risk and benefit. Blood Rev 2010;24(4-5):171-178

10 Kearon C, Akl EA, Ornelas J, et al. Antithrombotic therapy for VTE disease: CHEST guideline and expert panel report. Chest 2016;149(2):315-352

11 Kaufman JA, Kinney TB, Streiff MB, et al. Guidelines for the use of retrievable and convertible vena cava filters: report from the society of interventional radiology multidisciplinary consensus conference. World J Surg 2007;31:251-264

12 BrownJD, TalbertJC. Hospital variation and patient characteristics associated with vena cava filter use for venous thromboembolism. Pharmacoepidemiol Drug Saf 2016;25:64-65

13 Lee MJ, Valenti D, de Gregorio MA, Minocha J, Rimon U, Pellerin $O$. The CIRSE retrievable IVC filter registry: retrieval success rates in practice. Cardiovasc Intervent Radiol 2015;38(6):1502-1507

14 Oh K, Hingorani A. Outcomes and associated factors in malpractice litigation involving inferior vena cava filters. J Vasc Surg Venous Lymphat Disord 2018;6(4):541-544

15 Kaufman JA. Inferior vena cava filters: current and future concepts. Interv Cardiol Clin 2018;7(1):129-135

16 PREPIC Study Group. Eight-year follow-up of patients with permanent vena cava filters in the prevention of pulmonary embolism: the PREPIC (Prevention du Risque d'Embolie Pulmonaire par Interruption Cave) randomized study. Circulation 2005;112(3):416-422

17 Mismetti P, Laporte S, Pellerin O, et al; PREPIC2 Study Group. Effect of a retrievable inferior vena cava filter plus anticoagulation vs anticoagulation alone on risk of recurrent pulmonary embolism: a randomized clinical trial. JAMA 2015;313(16):1627-1635

18 Stein PD, Matta F. Vena cava filters in unstable elderly patients with acute pulmonary embolism. Am J Med 2014;127(3):222-225

19 White RH, Brunson A, Romano PS, Li Z, Wun T. Outcomes after vena cava filter use in noncancer patients with acute venous thromboembolism. Circulation 2016;133(21):2018-2029

20 Wadhwa V, Gutta NB, Trivedi PS, et al. In-hospital mortality benefit of inferior vena cava filters in patients with pulmonary embolism and congestive heart failure. AJR Am J Roentgenol 2018;211(3):672-676

21 Caplin DM, Nikolic B, Kalva SP, Ganguli S, Saad WE, Zuckerman DA; Society of Interventional Radiology Standards of Practice Committee. Quality improvement guidelines for the performance of inferior vena cava filter placement for the prevention of pulmonary embolism. J Vasc Interv Radiol 2011;22(11):1499-1506

22 Jia Z, Wu A, Tam M, Spain J, McKinney JM, Wang W. Caval penetration by inferior vena cava filters: a systematic literature review of clinical significance and management. Circulation 2015;132(10):944-952

23 Angel LF, Tapson V, Galgon RE, Restrepo MI, Kaufman J. Systematic review of the use of retrievable inferior vena cava filters. J Vasc Interv Radiol 2011;22(11):1522-1530.e3

24 Morales JP, Li X, Irony TZ, Ibrahim NG, Moynahan M, Cavanaugh KJ. Decision analysis of retrievable inferior vena cava filters in patients without pulmonary embolism. J Vasc Surg Venous Lymphat Disord 2013;1(4):376-384

25 Andreoli JM, Lewandowski RJ, Vogelzang RL, Ryu RK. Comparison of complication rates associated with permanent and retrievable inferior vena cava filters: a review of the MAUDE database. J Vasc Interv Radiol 2014;25(8):1181-1185

26 Deso SE, Idakoji IA, Kuo WT. Evidence-based evaluation of inferior vena cava filter complications based on filter type. Semin Intervent Radiol 2016;33(2):93-100

27 Eifler AC, Lewandowski RJ, Gupta R, et al. Optional or permanent: clinical factors that optimize inferior vena cava filter utilization. J Vasc Interv Radiol 2013;24(1):35-40 
28 Guez D, Hansberry DR, Eschelman DJ, et al. Inferior vena cava filter placement and retrieval rates among radiologists and nonradiologists. J Vasc Interv Radiol 2018;29(4):482-485

29 Medical MS-DRG 301: Peripheral vascular disorders (weight 0.6679 ) estimated reimbursement $\$ 8,059$ versus Surgical MS DRG-254: Other vascular procedures (weight 1.6609) estimated reimbursement $\$ 20,040$. n.d. Available at: https:// www.cms.gov/Research-Statistics-Data-and-Systems/ Research-Statistics-Data-and-Systems.html. Accessed October 11,2018

30 Prasad V, Rho J, Cifu A. The inferior vena cava filter: how could a medical device be so well accepted without any evidence of efficacy? JAMA Intern Med 2013;173(7):493-495, discussion 495

31 Desai KR, Lewandowski RJ, Salem R, et al. Retrieval of inferior vena cava filters with prolonged dwell time: a single-center experience in 648 retrieval procedures. JAMA Intern Med 2015;175(9):1572-1574

32 Kumar BCA, Chakraverty S, Zealley I. Removal of a permanent IVC filter. Cardiovasc Intervent Radiol 2006;29(1):124-125

33 Kearon C, Akl EA, Ornelas J, et al. Antithrombotic therapy for VTE. Chest 2016;149(2):315-352

34 Schulman S, Zondag M, Linkins L, et al. Recurrent venous thromboembolism in anticoagulated patients with cancer: management and short-term prognosis. J Thromb Haemost 2015;13(6):1010-1018

35 Carrier M, Le Gal G, Cho R, Tierney S, Rodger M, Lee AY. Dose escalation of low molecular weight heparin to manage recurrent venous thromboembolic events despite systemic anticoagulation in cancer patients. J Thromb Haemost 2009;7(5):760-765

36 Ahmad I, Yeddula K, Wicky S, Kalva SP. Clinical sequelae of thrombus in an inferior vena cava filter. Cardiovasc Intervent Radiol 2010;33(2):285-289

37 Habito CR, Kalva SP. Inferior vena cava filter thrombosis: a review of current concepts, evidence, and approach to management. Hosp Pract (1995) 2011;39(3):79-86

38 Vedantham S, Vesely TM, Parti N, et al. Endovascular recanalization of the thrombosed filter-bearing inferior vena cava. J Vasc Interv Radiol 2003;14(7):893-903

39 Alkhouli M, Morad M, Narins CR, Raza F, Bashir R. Inferior Vena Cava Thrombosis. JACC Cardiovasc Interv 2016;9(7):629-643

40 Kuo WT, Odegaard JI, Rosenberg JK, Hofmann LV. Laser-assisted removal of embedded vena cava filters: a 5-year firstin-human study. Chest 2017;151(2):417-424

41 Muñoz FJ, Mismetti P, Poggio R, et al; RIETE Investigators. Clinical outcome of patients with upper-extremity deep vein thrombosis: results from the RIETE Registry. Chest 2008;133(1):143-148

42 Joffe HV, Kucher N, Tapson VF, Goldhaber SZ; Deep Vein Thrombosis (DVT) FREE Steering Committee. Upper-extremity deep vein thrombosis: a prospective registry of 592 patients. Circulation 2004;110(12):1605-1611

43 Bleker SM, van Es N, Kleinjan A, et al. Current management strategies and long-term clinical outcomes of upper extremity venous thrombosis. J Thromb Haemost 2016;14(5):973-981

44 Kooij JD, van der Zant FM, van Beek EJ, Reekers JA. Pulmonary embolism in deep venous thrombosis of the upper extremity: more often in catheter-related thrombosis. Neth J Med $1997 ; 50(6): 238-242$
45 Ascher E, Hingorani A, Tsemekhin B, Yorkovich W, Gunduz Y. Lessons learned from a 6-year clinical experience with superior vena cava Greenfield filters. J Vasc Surg 2000;32(5):881-887

46 Owens CA, Bui JT, Knuttinen MG, Gaba RC, Carrillo TC. Pulmonary embolism from upper extremity deep vein thrombosis and the role of superior vena cava filters: a review of the literature. J Vasc Interv Radiol 2010;21(6):779-787

47 Carlon TA, Sudheendra D. Interventional therapy for upper extremity deep vein thrombosis. Semin Intervent Radiol 2017;34(1):54-60

48 Singer AJ, Wilson S. Reversal strategies for newer oral anticoagulants. AACN Adv Crit Care 2017;28(4):322-331

49 Rogers FB, Strindberg G, Shackford SR, et al. Five-year follow-up of prophylactic vena cava filters in high-risk trauma patients. Arch Surg 1998;133(4):406-411, discussion 412

50 Haut ER, Garcia LJ, Shihab HM, et al. The effectiveness of prophylactic inferior vena cava filters in trauma patients: a systematic review and meta-analysis. JAMA Surg 2014;149(2):194-202

51 Kidane B, Madani AM, Vogt K, Girotti M, Malthaner RA, Parry NG. The use of prophylactic inferior vena cava filters in trauma patients: a systematic review. Injury 2012;43(5):542-547

52 Hemmila MR, Osborne NH, Henke PK, et al. Prophylactic inferior vena cava filter placement does not result in a survival benefit for trauma patients. Ann Surg 2015;262(4):577-585

53 Cook AD, Gross BW, Osler TM, et al. Vena cava filter use in trauma and rates of pulmonary embolism, 2003-2015. JAMA Surg 2017;152(8):724-732

54 Gargiulo NJ III, Veith FJ, Lipsitz EC, Suggs WD, Ohki T, Goodman E. Experience with inferior vena cava filter placement in patients undergoing open gastric bypass procedures. J Vasc Surg 2006;44(6):1301-1305

55 Vaziri K, Bhanot P, Hungness ES, Morasch MD, Prystowsky JB, Nagle AP. Retrievable inferior vena cava filters in highrisk patients undergoing bariatric surgery. Surg Endosc 2009;23(10):2203-2207

56 Rowland SP, Dharmarajah B, Moore HM, et al. Inferior vena cava filters for prevention of venous thromboembolism in obese patients undergoing bariatric surgery: a systematic review. Ann Surg 2015;261(1):35-45

57 Harris SA, Velineni R, Davies AH. Inferior vena cava filters in pregnancy: a systematic review. J Vasc Interv Radiol 2016;27(3):354-60.e8

58 Noble SI, Shelley MD, Coles B, Williams SM, Wilcock A, Johnson MJ; Association for Palliative Medicine for Great Britain and Ireland. Management of venous thromboembolism in patients with advanced cancer: a systematic review and meta-analysis. Lancet Oncol 2008;9(6):577-584

59 Barginear MF, Gralla RJ, Bradley TP, et al. Investigating the benefit of adding a vena cava filter to anticoagulation with fondaparinux sodium in patients with cancer and venous thromboembolism in a prospective randomized clinical trial. Support Care Cancer 2012;20(11):2865-2872 